Bull. Fac. Agric., Cairo Univ., 65:236-242 (2014).

\title{
INFLUENCE OF LINT GRADE AND IMPURITIES ON THE EGYPTIAN COTTONS CLEANABILITY
}

(Received: 12.5.2014)

\author{
By \\ Kh .M. Hussein, I. A. Ebaido and Y. Sh. Abd-EIrahman \\ Cotton Research Institute, Agricultural Research Center, Giza, Egypt
}

\begin{abstract}
The present investigation was conducted to evaluate the feasibility of cleaning lint cotton and monitoring the behavior of the Egyptian cotton to cleaning. Materials used in this study included the extra-long and long staple varieties of the Egyptian cotton with wide range of lint grades. HVI instrument was used to determine lint grade factors. MDTA3 with 2 passages and a total of 10 grams were used regarding impurity contents and degree of the cleaning evaluation.

The results showed high variation of impurities within the same variety, degree of cleaning and cleanability. The same nominal grade for different varieties has different values of these measures, especially the lowest grade FGF. Any increase in trash, dust and fiber fragments resulted in a decrease of cleanability and the degree of cleaning. Reflectance percentage and micronaire value associated positively with cleanability and degree of cleaning. The values of cleanability and degree of cleaning seemed to be the same for extra-long and long staple categories. All cottons in this study were in the "Average" class of the degree of cleaning, except for the finest cotton variety Giza 93, which exhibits the Good class.
\end{abstract}

Key words: cleanability, degree of cleaning, Egyptian cotton grades, impurities

\section{INTRODUCTION}

The trend now in the expansion of cotton grading and marketing process is maintaining an acceptable degree of quality. Therefore, greater stresses and demands are sited on the lint content of foreign matter. Leaf grade is affected by variety, harvesting method, and ginning practices, which is defined as an indicator of the amount of non-lint content (plant or trash material). Leaf grade is directly proportional to the amount of trash present with cotton fibers as mentioned in Cotton Program 2001. It has also added that leaf grade as a purity measure, indicates the quantity of plant material in the lint.

Nickerson et al. (1959), stressed that the non lint content of cotton increased sharply as the cotton grade decreased. Lord (1961), concluded that the amount of foreign matter varied according to the type of cotton, the condition of growth, the method of picking and the efficiency of ginning process. He found a negative association between seed cotton grade and trash content.

The MDTA3 is the only instrument, which can be flexibly used for raw material evaluation
Optimization of the blend, evaluation, of the cleaning machinery, production of mélanges and determination of stickiness.

Manually the extra-long and long staple cotton harvested in Egypt results in a substantial quantities of trash material such as: stems, leaves, hulls and bracts, as defined by the American Society for Testing and Materials, ASTM, (1967). It also stated that the visible waste is the trash material and nonspinable fibers such as fibers attached to motes and seed coat fragments.

Despite technology, rigorous mechanical processing remains a necessity in order to successfully open and clean, because the removal of impurities is usually accompanied by shortening of the length distribution, fiber loss, formation of neps, fiber breaking and other damages (Mangialardi, 1992).

Perkins, (1971), Perkins and Bragg (1977) and Hector and Hodkinson (1989), concluded that the well-known non-fibrous materials are trash and seed coat fragments. They also found that there is man-induced surface contaminants of cotton fibers that may come from excessive levels of greases and oils introduced from 
machinery used in the harvesting and ginning processes, and various chemicals applied to the cotton prior to harvesting such as herbicides, insecticides, and defoliants. Perkins and Bragg (1977) and Hector and Hodkinson (1989), mentioned that contaminants directly affect the quality of cotton fibers and spinning performance, which in turn adversely affect its market value.

The amount of trash material has a direct adverse effect on the cotton grade whether grade of seed cotton or lint cotton, therefore, Garner and Baker (1977), emphasized that trash materials must be removed in the early stages before ginning by using a pre-cleaning extractor which leads to an improvement in the cotton grade.

Very often cotton bales, which seem to be relatively clean, cause the greatest problems. The trash of these cotton bales often consists mostly of seed coat fragments, which can only be separated with difficulties, or even not at all. If the high trash content in fiber material consists primarily of leaf particles, the raw material can be easily cleaned (Krifa et al., 2002).

Hussein (2001), characterized the trash content of E-LS and LS Egyptian cottons using the MTM trash analyzer as follow; \% leaf, \% fiber fragments, $\%$ dust, $\%$ visible trash ,\% invisible trash and the \% total trash. He found significant differences between trash components obtained for E-LS and LS Egyptian cotton varieties, lint grades and their interaction.

Leifeld (1988) stated that since fiber material with low trash content is usually more expensive than material with higher trash content, knowing the cleanability of the fiber material permits significant cost savings.

Since the trash materials in cotton directly affect its potential profitability, therefore, in the textile community, it is very important conventionally to monitore this trash materials using a trash analyzer instrument. Fortier et al. (2010) explained that the ability to classify cotton grade and ultimately remove cotton trash and foreign matter present with cotton lint has potential to increase the market value and durability of cotton from its conversion of fiber to yarn.

Nasir et al. (2012), found that fiber physical properties, yarn processing efficiency and quality of the end product potentially affect the possible trash practiced in handling during the picking, ginning and baling processes. In this respect, Brushwood (2005), found it represents approximately $3 \%$ of the fiber weight.

Therefore, the present investigation aim to study the effect of the different lint cotton grade on the feasibility of cleaning lint cotton and monitoring the response of the Egyptian cotton to cleaning.

\section{MATERIAL AND METHODS}

To implement this study, the material used comprised the Egyptian cotton varieties in conformity with the local practice in Egypt as follows, Extra-Long Staple (E-LS) category (Giza 88, Giza 92, and Giza 93) and Long Staple (LS) category (Giza 80, Giza 86, and Giza 90).

From each variety, four lint cotton grades according to the Egyptian cotton grading system ranging from Good to Fully Good (G/FG) grade down to Fully Good Fair (FGF), in decrements of $1 / 2$ grade were used.

To facilitate the statistical procedures, the grades were converted into a numerical code according to Kamal and Ragab, (1995) as follows:

\begin{tabular}{|c|c|}
\hline Egyptian cotton grade $=$ Abbreviation & Code \\
\hline Good to Fully Good $=\mathrm{G} / \mathrm{FG}$ & 15 \\
\hline Good $=\mathrm{G}$ & 13 \\
\hline Fully Good Fair /Good = FGF/G & 11 \\
\hline Fully Good Fair $=$ FGF & 9 \\
\hline
\end{tabular}

Samples representing the four grades of all varieties were taken from the Egyptian cotton production and marketing seasons of 2012 and 2013.

All samples have been tested regarding measuring impurity content i.e., trash (T), dust (D) and fiber fragments (FF) using the control device "Micro dust Trash Analyzer (MDTA3)" according to ASTM-D. 2812, 2012a. This was achieved by opening fibers of the sample (5: 10 g) in a similar way to carding. Impurities are separated into T, D and FF, and finally the fibers are formed into a homogeneous fiber ring of 1 meter in length.

Degree of cleaning and cleanability were derived as follow:

Degree of cleaning $(\mathrm{CD})=\mathrm{T}_{2} / \mathrm{T}_{1} * 100$

Cleanability $(\mathrm{C})=\mathrm{T}_{1} /\left(\mathrm{T}_{1}+\mathrm{T}_{2}\right) * 100$

Where $T_{1}=$ percentage of impurities at the input raw cotton; $\mathrm{T}_{2}=$ percentage of eliminated impurities.

Micronaire value (MIC) and brightness of cotton in terms of reflectance percentage (Rd \%) were determined using HVI instrument 
according to ASTM - D.5867-2012b, 17761998, 2253-66. The measurements of color, micronaire and impurities attributes of the materials used in the present study were conducted at the laboratories of the Cotton Research Institute, Agricultural Research Center, Giza-Egypt.

Collected data were subjected to the proper statistical analysis of descriptive statistics in (Table 1) and correlation according to Gomez and Gomez (1984) using the computer statistical software package SAS V.9.1, (2004).
3; no other testing instrument is measures this important parameter.

In respect to expected micronaire value for the finest extra-long cotton variety Giza 93 which valued 3.1. Within the same variety, high variation of impurities, degree of cleaning, cleanability, and reflectance percentage micronaire value, were detected.

Data in Table (2) show that any increase in impurities, i.e., fiber fragments, dust and trash resulted in decrease of cleanability and degree of cleaning. On the other hand, the decrease in lint

Table (1): Descriptive Statistics for cleanability, degree of cleaning, fiber fragments, dust, trash, reflectance percentage and micronaire value of the cotton varieties

\begin{tabular}{|c|c|c|c|c|c|c|c|}
\hline Variable & Mean & SE & SD & CV\% & MIN & MAX & Range \\
\hline $\mathrm{C}$ & 77.54 & 1.14 & 5.57 & 7.19 & 68.63 & 85.19 & 16.56 \\
\hline CD & 29.61 & 1.93 & 9.46 & 31.93 & 17.39 & 45.71 & 28.32 \\
\hline FF & 0.72 & 0.06 & 0.31 & 43.80 & 0.42 & 1.42 & 1.00 \\
\hline D & 0.71 & 0.05 & 0.27 & 40.46 & 0.14 & 1.28 & 1.14 \\
\hline $\mathbf{T}$ & 4.67 & 0.39 & 1.94 & 41.59 & 2.14 & 7.85 & 5.71 \\
\hline Rd \% & 65.86 & 1.16 & 5.71 & 8.66 & 55.20 & 77.80 & 22.60 \\
\hline MIC & 3.83 & 0.10 & 0.49 & 12.81 & 2.80 & 4.70 & 1.90 \\
\hline
\end{tabular}

$\mathrm{C}=$ Cleanability, $\mathrm{CD}=$ Degree of cleaning, FF = Fiber fragments, $\mathrm{D}=$ Dust, $\mathrm{T}=\mathrm{Trash}, \mathrm{Rd} \%=$ Reflectance percentage, $\mathrm{MIC}=$ Micronaire value.

\section{RESULTS AND DISCUSSION}

Row cotton contains various kinds of trash such as leaf, bark and seed coat particles. The content of each of these trash categories is highly dependent on the origin of the cotton and its harvesting method. The MDTA 3 not only determines the actual trash content, it also allows visual assessment to ascertain its precise contents. The clear advantage of the gravimetrical measurement of trash as compared to the optical measurement of the HVI is that the actual trash content is measured, whereas the HVI simply provides information relating to the number of trash points and the trash area on the surface of the test sample.

Specifications of observations pertaining to the six varieties (G. 88 , G. 92 , G. 93, G. 86, G. 80 and G. 90) and four lint grades (G/FG, G, FGF/G and FGF) for impurity characters and grade factors of relevance to the study are shown in Table (2). Results depict wide differences among lint grades for impurity, cleanability and grade factors. Both extra-long stable varieties namely G. 88, G. 92 and G. 93 and long staple varieties (G. 86, G. 80 and G. 90) are very close with no apparent significance in each of trash, fiber fragment, dust, clean ability, degree of cleaning, cleaning efficiency, reflectance percentage and micronaire value. The cleanability can only be measured by the MDTA cotton grade resulted in decrease of cleanability and degree of cleaning. Note that the grade factors, i.e., reflectance percentage and micronaire value that associated positively with lint cotton grade, had met the same trend with cleanability and degree of cleaning. It is worth mentioning that the worst cleanability is due to the fragments in lint but only slightly affects their number (Frey and Schneide, 1989). This indicates that lint cleaners, in addition to removing fragments may create new fragments by breaking up some of those present.

Difficulties in opening and separating fibers after one passage of the sample in the control device MDTA 3.

The same nominal grade for different varieties had different values of impurities and grade factors. Results indicate wide differences among lint cotton grades for cleanability and degree of cleaning. The degree of cleaning and cleanability showed close values for extra-long and long staple cottons. This is true except for the lint grade Good, whereas the extra-long staple class exhibits higher values than the long staple category (Figure 1 and Figure 2).

Concerning to the effect of fiber fragment particles, it increased significantly in the cotton industry because the demand for improving fabric quality has increased. Generally, the lint cleaning considerably decreases the weight of 


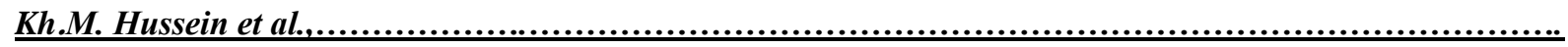

Table (2): Effect of lint cotton grades for extra-long and long staple Egyptian cotton varieties on impurities (FF, D and $\mathrm{T})$, cleanability $(\mathrm{C})$, degree of cleaning $(\mathrm{CD})$, reflectance percentage $(\mathrm{Rd} \%)$ and micronaire value (MIC)

\begin{tabular}{|c|c|c|c|c|c|c|c|c|}
\hline \multirow{2}{*}{ Varieties } & \multirow{2}{*}{ Grade } & \multicolumn{7}{|c|}{ Variable } \\
\hline & & FF & D & $\mathbf{T}$ & $\mathbf{C}$ & CD & Rd\% & MIC \\
\hline \multirow{4}{*}{ 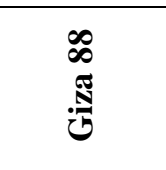 } & G/FG & 0.43 & 0.43 & 2.43 & 85.19 & 43.08 & 68.90 & 4.50 \\
\hline & G & 0.57 & 0.57 & 3.86 & $\mathbf{7 9 . 5 5}$ & 31.91 & 67.70 & 4.20 \\
\hline & FGF/G & 0.71 & 0.86 & 5.14 & 75.81 & 25.71 & 64.20 & 3.80 \\
\hline & FGF & 1.29 & 1.00 & 7.00 & 69.89 & 17.39 & 62.90 & 3.60 \\
\hline \multicolumn{2}{|c|}{ Average } & 0.75 & 0.71 & 4.61 & 77.61 & 29.52 & 65.93 & 4.03 \\
\hline \multirow{4}{*}{ 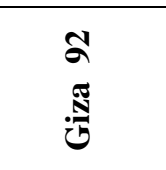 } & G/FG & 0.43 & 0.57 & 2.29 & 85.19 & 42.62 & 77.80 & 3.90 \\
\hline & G & 0.64 & 0.66 & 3.49 & 79.95 & 33.70 & 75.10 & 3.70 \\
\hline & FGF/G & 0.86 & 0.86 & 4.86 & 74.80 & 25.07 & 70.20 & 3.50 \\
\hline & FGF & 0.86 & 1.00 & 6.86 & 70.11 & 17.39 & 68.70 & 3.30 \\
\hline \multicolumn{2}{|c|}{ Average } & 0.70 & 0.77 & 4.37 & 77.51 & 29.70 & 72.95 & 3.60 \\
\hline \multirow{4}{*}{ 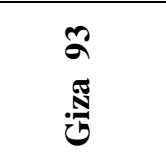 } & G/FG & 0.43 & 0.57 & 2.57 & 83.33 & 45.71 & 68.00 & 3.30 \\
\hline & $\mathbf{G}$ & 0.57 & 0.71 & 3.57 & 80.38 & 35.19 & 66.90 & 3.20 \\
\hline & FGF/G & 0.86 & 1.00 & 5.86 & 73.97 & 24.41 & 65.30 & 3.10 \\
\hline & FGF & 1.14 & 1.29 & 7.57 & 68.63 & 20.00 & 63.80 & 2.80 \\
\hline \multicolumn{2}{|c|}{$\frac{1}{\text { Average }}$} & 0.73 & 0.79 & 4.62 & 76.58 & 31.33 & 66.00 & 3.10 \\
\hline \multicolumn{2}{|c|}{ Grand Average } & 0.72 & 0.69 & 4.67 & 77.23 & 30.18 & 68.29 & 3.58 \\
\hline \multicolumn{2}{|c|}{ MSD 5\% } & 0.31 & 0.28 & 0.89 & 2.19 & 3.73 & 10.91 & 1.23 \\
\hline \multirow{4}{*}{ 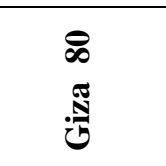 } & G/FG & 0.43 & 0.43 & 2.14 & 84.00 & 42.03 & 65.70 & 4.20 \\
\hline & $\mathbf{G}$ & 0.43 & 0.43 & 3.29 & 80.56 & 30.36 & 61.00 & 4.00 \\
\hline & FGF/G & 1.00 & 1.00 & 6.00 & 76.71 & 24.14 & $\mathbf{5 7 . 5 0}$ & 3.80 \\
\hline & FGF & 1.43 & 1.00 & 7.43 & 70.41 & 19.05 & 55.30 & 3.50 \\
\hline \multicolumn{2}{|c|}{ Average } & 0.82 & 0.71 & 4.71 & 77.92 & 28.89 & 59.88 & 3.88 \\
\hline \multirow{4}{*}{\begin{tabular}{l}
$\infty$ \\
$\mathbb{N}$ \\
$\mathbb{N}$ \\
\multirow{2}{*}{}
\end{tabular}} & G/FG & 0.43 & 0.43 & 2.29 & 84.62 & 41.94 & 74.70 & 4.70 \\
\hline & $\mathbf{G}$ & 0.43 & 0.43 & 3.71 & 80.00 & 31.82 & 70.10 & 4.50 \\
\hline & FGF/G & 0.57 & 0.57 & 5.14 & 75.86 & 25.00 & 66.80 & 4.10 \\
\hline & FGF & 0.86 & 0.71 & 7.86 & 70.45 & 18.18 & 65.00 & 3.90 \\
\hline \multicolumn{2}{|c|}{ Average } & 0.57 & $\mathbf{0 . 5 3}$ & 4.75 & 77.73 & 29.23 & 69.15 & 4.30 \\
\hline \multirow{4}{*}{ 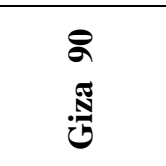 } & G/FG & 0.43 & 0.43 & 2.43 & 85.19 & 42.65 & 66.90 & 4.50 \\
\hline & G & 0.57 & 0.57 & 3.86 & 79.55 & $\mathbf{3 0 . 2 3}$ & 62.90 & 4.20 \\
\hline & FGF/G & 0.57 & 0.57 & 5.00 & 76.79 & 25.71 & 60.10 & 3.90 \\
\hline & FGF & 1.29 & 1.00 & 7.43 & 70.10 & 17.39 & 55.20 & 3.60 \\
\hline \multicolumn{2}{|c|}{ Average } & 0.71 & 0.64 & 4.68 & 77.90 & 29.00 & 61.28 & 4.05 \\
\hline \multicolumn{2}{|c|}{ Grand Average } & 0.70 & 0.63 & 4.71 & 77.85 & 29.04 & 63.43 & 4.08 \\
\hline \multicolumn{2}{|c|}{ Total Average } & 0.72 & 0.71 & 4.67 & 77.54 & 29.61 & 65.86 & 3.83 \\
\hline \multicolumn{2}{|c|}{ MSD 5\% } & 0.51 & 0.40 & 0.88 & 1.24 & 1.95 & 13.18 & 0.57 \\
\hline
\end{tabular}

fragments in lint but only slightly affects their number (Frey and Schneider,1989). This indicates that lint cleaners, in addition to removing fragments may create new fragments by breaking up some of those present.

The degree of cleaning is influenced not only by the lint characteristics in intermediate products but also by the mechanical handling of fibers. This may be due to the difficult to clean cotton (poor cleanability) and / or if the machine has a lower cleaning efficiency, cotton will have a lower degree of cleaning (Schlichter and Kuschel, 1995).

All cotton varieties in this study are in the average class $(\mathrm{CD}=29 \%)$, except for Giza 93, which exhibits the Good class of degree of cleaning $(\mathrm{CD}=31.33 \%)$. The Very good degree of cleaning is for the highest grade G/FG (CD > $40 \%$ ) and the bad class is for the lowest grade FGF (CD < 20\%). According to Uster (2001) the degree of cleaning can be classified as shown in Table (3).

Table(3):Classification of degree of cleaning (\%) of row cotton

\begin{tabular}{|l|l|}
\hline Class & Interpretation \\
\hline$>\mathbf{4 0} \%$ & Very good \\
\hline $\mathbf{3 0} \%-\mathbf{4 0} \%$ & Good \\
\hline $\mathbf{2 0} \%-\mathbf{3 0} \%$ & Average \\
\hline $\mathbf{1 0} \%-\mathbf{2 0} \%$ & Bad \\
\hline$<10 \%$ & Very Bad \\
\hline
\end{tabular}




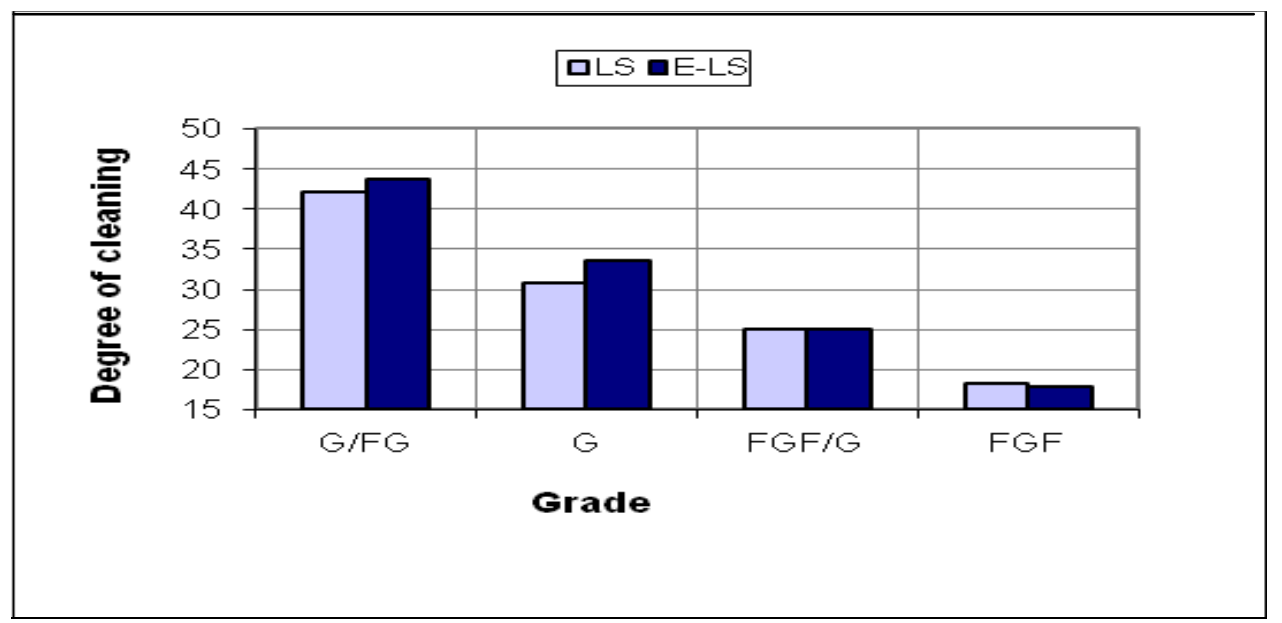

Fig.(1): Relationship between lint grade and degree of cleaning for Extra-long and long staple cottons.

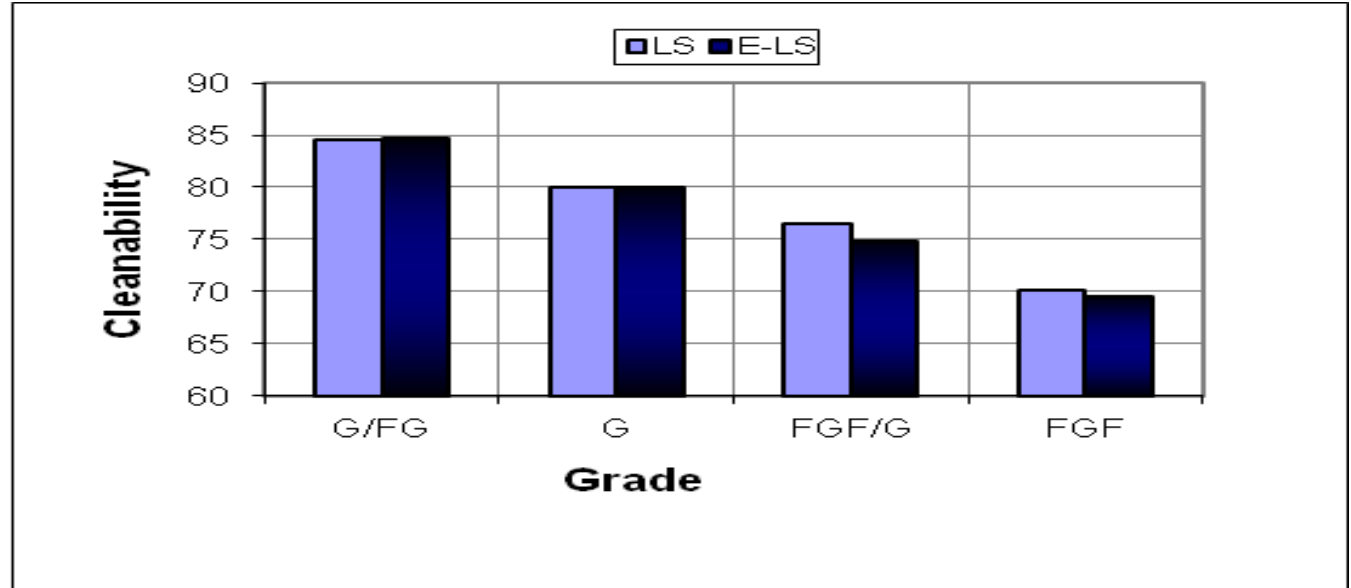

Fig.(2): The relationship between lint grade and the cleanability For Extra-long and long staple cottons.

Correlation matrix among lint cotton grade, fiber fragment, dust, trash, cleanability, degree of cleaning, reflectance percentage and micronaire value are shown in Table (4). The highest value of the correlation coefficients were detected between cleanability and each of the lint grade and degree of cleaning $(\mathrm{r} \approx 1.00)$. Moreover, the degree of cleaning showed positive association with impurities, on the other hand, negative association was detected between the cleanability and impurities traits (FF, D and T).

All correlation coefficients between different traits were significant or highly significant, except insignificant association between $\mathrm{Rd} \%$ and micronaire value.

Correlation coefficient between each of the reflectance percentage and micronaire value with cleanability and degree of cleaning value were moderately positive or negative values ( $\mathrm{r}$ : value ranged from (- 0.530: 0.630).

\section{Conclusion}

By testing a sample on the MDTA 3 the gravimetrical content of trash, dust and fiber fragments was determined. The MDTA 3 is the only instrument to measure the cleanability.

Egyptian cottons do not differ much in terms of cleanability, with the exception of fine cottons, which are difficult to clean. Cotton grades have a significant impact on the cleanability, as the low grade has a poor cleanability. The degree of cleaning is an interesting characteristic for the machine. The cleanability strongly depends on the trash, seed coat fragments and the micronaire value. The determination of cleanability allows to compare the effect of cleaning lines on the decrease and the fragmentation of trash, and to evaluate the cleaning efficiency. Besides, it is possible to analyze the cleaning efficiency of machines at reasonable times and with a few staff in order to compare their function status for a better follow-up. 
Table (4): Correlation coefficients among fiber fragment, dust, trash, cleanability, degree of cleaning, reflectance percentage and micronaire value

\begin{tabular}{|c|c|c|c|c|c|c|c|}
\hline & Grade & FF & D & T & C & CD & Rd\% \\
\hline FF & $\mathbf{- 0 . 8 6 1}^{* *}$ & & & & & & \\
\hline D & $\mathbf{- 0 . 6 2 8}^{* *}$ & $\mathbf{0 . 7 6 1}^{* *}$ & & & & & \\
\hline T & $\mathbf{- 0 . 9 8 2 ~}^{* * *}$ & $\mathbf{0 . 8 8 7}^{* *}$ & $\mathbf{0 . 6 1 7}^{* *}$ & & & & \\
\hline C & $\mathbf{0 . 9 9 7}^{* *}$ & $\mathbf{- 0 . 8 7 3}^{* *}$ & $\mathbf{- 0 . 6 5 7}^{* *}$ & $\mathbf{- 0 . 9 8}^{* * *}$ & & & \\
\hline CD & $\mathbf{0 . 9 8 4}^{* *}$ & $\mathbf{0 . 8 8 2}^{* *}$ & $\mathbf{0 . 6 5 9}^{* *}$ & $\mathbf{0 . 9 8 1}^{* *}$ & $\mathbf{0 . 9 9 8}^{* *}$ & & \\
\hline Rd\% & $\mathbf{0 . 5 5 7}^{* *}$ & $\mathbf{- 0 . 6 1 1}^{* *}$ & $\mathbf{- 0 . 3 8 5}^{* *}$ & $\mathbf{- 0 . 9 9 8}^{* *}$ & $\mathbf{0 . 5 4 5}^{* *}$ & $\mathbf{- 0 . 5 3 6}^{* *}$ & \\
\hline MIC & $\mathbf{0 . 5 7 5}^{* *}$ & $\mathbf{- 0 . 5 8 2}^{* *}$ & $\mathbf{- 0 . 7 9 2}^{* *}$ & $\mathbf{- 0 . 5 7 3}^{* *}$ & $\mathbf{0 . 6 2 6}^{* *}$ & $\mathbf{- 0 . 6 2 6}^{* *}$ & $\mathbf{0 . 2 5 1}^{\text {ns }}$ \\
\hline
\end{tabular}

\section{REFERENCES}

American Society for Testing and Materials (1967). Standards on textile materials. A.S.T.M., Vol.24,Philadelphia,PA,USA.

American Society for Testing and Materials, ASTM. (2012a). Standard test method for non-lint content of cotton (D2812). In Annual Book of ASTM Standards. ASTM International, West Conshohocken, PA.

American Society for Testing and Materials ASTM. (2012b). Standard test method for measurement of physical properties of cotton fibers by high volume instruments (D5867). In Annual Book of ASTM Standards. ASTM International,West Conshohocken, PA.

Brushwood D. E. (2005). Changes in nonfibrous material content of cotton during yarn processing, T. R. J.75:1, 616-621.

Cotton Program (2001).The classification of cotton. U.S. Department of Agriculture, Agricultural Marketing Service,Washington D.C.

Fortier C., Rodgers J., Cintron M. S.,Cui X. and Foulk J. (2010). Identification of cotton and cotton trash components by fourier transform near-infrared spectroscopy. Textile Res. J., 81,: 230-238.

Frey M. and Schneide U.(1989).Possibilities of Removing Seed Coat Fragments and Attached Fiber in the Spinning Process, Melli and Textilberichte Int. Text .Rep., 70:18-22.

Garner W. E. and Baker R.V.(1977).Cleaning and extracting.Cotton ginners handbook. Agricultural research service, U.S.D.A. Washington, D.C. 503, :18-29.

Gomez K.A. and Gomez A.A. (1984). Statistical Procedures for Agricultural Research $2^{\text {nd }}$ Ed. John Wiley and Sons, New York

Hector D. J. and Hodkinson I. D. (1989). Stickiness in cotton. International Cotton
Advisory C. R. Article on Cotton R., (2): 44. CAB I.,Wallingford, Oxon, OX10 8DE,U. K.

Hussien K. M. (2001). Foreign matter content and neps in lint cotton in relation to lint cotton grade and yarn physical properties. M.Sc.Thesis, Fac. of Agric. Al-Azhar Univ. Egypt.

Kamal M.M. and Ragab M.T. (1995). Numerical quantification of lint grade in Egyptian cotton. Egy. J. Agric. Res.; 73 (3) 723-736.

Krifa M. Frydrych R and Goze E. (2002) .Seed coat fragments: The consequences of carding and the impact of attached fibers. Text. Res. J., 72: 37-41.

Leifeld F. (1988). The influence factor "C" of cotton in the cleaning process, Melliand Textilberichte, Int. Text. Rep., 69: 162.

Lord E. (1961). Manual of cotton spinning. Thecharacteristics of raw cotton. The Tex. Inst.,Butterworths,II- I: 234-273. Manchester, London,UK.

Mangialardi G. J. Jr. (1992). Preliminary search for new lint cleaning systems. 1413-1416, In Proc. Beltwide Cotton Conf., Nashville, TN. 6-10 January.

Nasir M., Muhammad Q. T., Iqbal D., Khan M. A. and Wajid I.(2012). Effect of different locations, varieties and micronaire values upon the non-cellulosic and metal contents of cotton. J.chem.Soc.Pak., 34(1):15-18

Nickerson O., Temaszweek J. J. and Elba F. F. (1959). Cotton grade studied; Trash and colour. The Empire Cotton G.R.,39(4): 304.

Perkins H. H. Jr. (1971). Determination of seed-coat fragments in cotton by solvent-extraction and infrared spectroscopy analysis. T. R. J. 41(7): 559-563.

Perkins H. H. Jr. and Bragg C. K. (1977). Effects of oil contamination on cotton quality: methods of analysis and characterization of contamination. Textile Research Journal 47(4): 271-277. 
SAS. (2004). SAS version 9.1. User's guide. Cary, NC: SAS institute, Inc.

Schlichter S. and Kuschel A. (1995).Recent findings on the cleanability of cotton. melliand textilberichte (Englisch); 76, E 49.

Uster (2001). Advanced fiber information system (Application handbook), Zellweger Uster, Inc.

$$
\text { خلاقة رتبة القطن ومحتوى الثوائب بقابلية الأقطان المصرية للتنظف }
$$

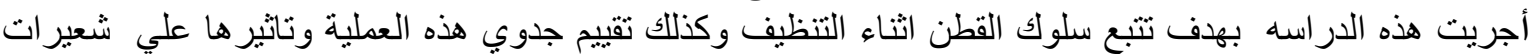

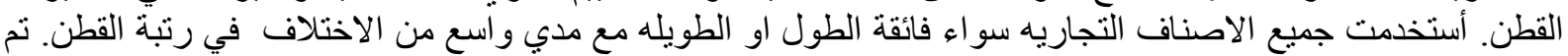

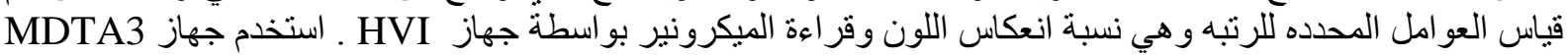

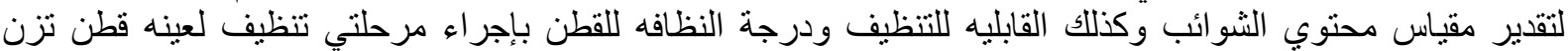

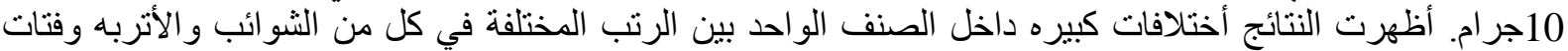

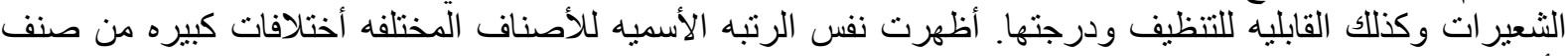

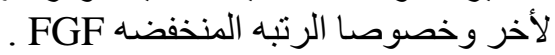

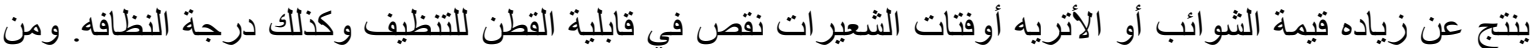

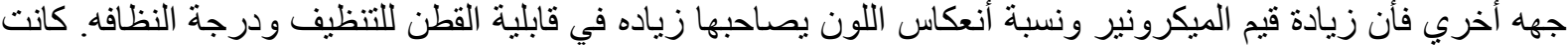

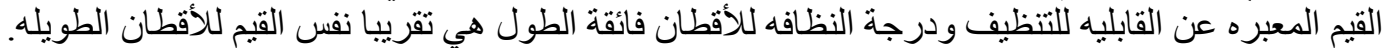

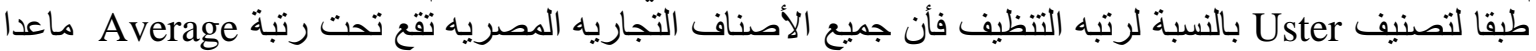

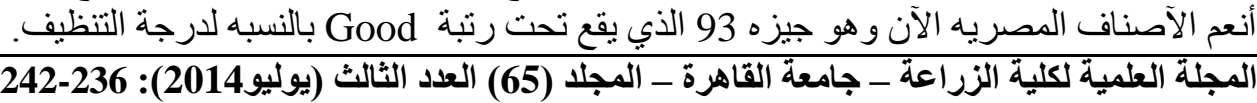

